\title{
THE COMPARISON BETWEEN THE IDENTITY STRUCTURE OF THE SOCIETY AND THE PHYSICAL STRUCTURE OF THE CITY
}

\author{
Farnaz JAVADI ${ }^{\mathrm{a}}$, Hossein NOORMOHAMADZAD ${ }^{\mathrm{b}}$ \\ aUrbanism, Yazd University, 181 Rajayee 29, Farhangshahr Ave. Shiraz, Fars, 7185955845, Iran \\ ${ }^{b}$ Urbanism, Yazd University, 3 Honar St. Ostad Ahmad Aram St. Safayie, Yazd, Yazd, 89158-17139, Iran \\ E-mails: ${ }^{1}$ javadifarnaz@yahoo.com; ${ }^{2}$ nourm@yazd.ac.ir (corresponding author)
}

Receveid 14 September 2016; accepted 20 December 2016

\begin{abstract}
The concept of identity has the potential to be interpreted from the aspect of any field and according to requirements and abilities of that. Identity is defined as language, art, and thought of any phenomenon, and the relations between these components in an environment. These relations represent a range of similarities and dissimilarities. Structure is one of the concepts that can be tracked in different phenomena. Identity is a total, consisting of language, art, and thought that are related to each other by transformators, around regulators, in adherence to principles, which create the identity structure. Likewise, the physical structure of the city is the outcome of structure of its components that are related to each other by transformators, around regulators and in adherence to principles. This study aims to find out whether the identity structure of the society is in accordance with the physical structure of the city? The study has been performed by descriptive and comparative methods. Results show that the identity structure of the society is corresponded to the physical structure of the city in principles, components and constituents. As a result, the identity structure of the society is in accordance with the physical structure of the city.
\end{abstract}

Keywords: structure, identity, physique, identity structure, physical structure, components, transformators, regulators, principles.

\section{Introduction}

The term structure became an important word in various fields of knowledge by Ferdinand de Saussure, a Swiss linguist (Meghdadi 2014). Saussure expressed that in linguistic process, in addition to the history, there is a system with balanced rules which dominates on elements (Piaget 2005). This system of sings is called language structure. After the linguistics, constructivism was introduced into other fields including anthropology, geography, sociology, economics, psychology, history, philosophy, and art. The most appropriate form of constructivism was appeared in studies and researches of Claude Levi-Strauss (Partovi 1999). Strauss believes that constructivism is an attempt to find the unchangeable element among superficial distinctions (Ahmadi 2003). Following this process, constructivism, which was emerged in the early 1950s through the discussion between SIAM and TeamX as a method in architecture and urbanism, was corresponded to Strauss's thought. With the development of constructivism in architecture and urbanism, the two other currents of thoughts had won the special position: Brutalism and formalism (Partovi 1999). Noam Chomsky continued current of thoughts which had been performed by earlier scholars such as Ferdinand de Saussure and Louis Hjelmslev, by his language theory (Lotfi 2005). Chomsky, by criticizing constructivism based on linguistic data, has introduced the language grammar as a set of certain rules which can produce all possible sentences in a particular language (Poorafkari, Kianpour 2006). In 1957, Chomsky provided a simple set of rules in "generative theory of grammar" which could illustrate the grammatical structure of sentences of any language (Grey 2004 as cited in Lotfi 2005).

The identity issue, has a long history through the attempt of giving the answer to the question "who am I?" The question not only has occupied the mind of literati and philosophers, but also the ordinary people and they are thinking to find an answer to it (Motavaf 2007). 
With the passage of time and the change of attitude to the world, the perception of identity term has changed. In pre-modern era, from the Heidegger's viewpoint, the human was an image which could be seen from the Gods' eyes, and his/her identity is a product of a powerful and pre-defined system of religious and mythological beliefs. In modern era, traditional criteria of identity evaluation were changed. In the identity issue, a reference was proposed as "subject". In the modern era, identity means the illustration of human origin and also introduction of human against the nature. In modern thought, the identity concept is defined like other concepts in a clear, explicit, pure, and without mix form. The thought based on modern explicit distinctions, takes the basis of identification in decisive resolutions of "we and others", and thus, separates cultures from each other. In the post-modernism era, notion of identity as a fixed, universal and unique issue has been challenged. Recognition of sub-culture and diverse identities, criticizes the modern fixed identity. In post-modernism thought, humans affect each other and also are influenced by each other, and any attempt to define identity exclusively is meaningless. Identity neither belongs to the individual, nor is a unique collective identity. Identity is not intrinsic; it is built in the human-environment interaction. In other words, we mean identity construction, not identification. Post-modern pluralistic human does not seek his/ her missing identity, but he/she is trying to build his/ her special identity (Ghotbi 2008).

The term physique has entered other sciences from biology (Skidmore 1993). The physique concept which has been used in urbanism is also based on biology. The terms physique and physical structure benefit from the thought that a physique is consisted of some parts and each part serves other parts and is considered as their supplement (Bazrgar 2003). Structuralism has influenced the physique and also physical structure at the beginning of the 1960s. Therefore, given the provided discussions in this era, it has been found that cities have been constructed of various structures including society structure, economic structure, and physical structure and so on (Bazrgar 2003). TeamX, Brutalism, Neo-Brutalism, and researchers such as Christopher Alexander, Balkrishna V. Doshi, Edmond Bacon, Fumihiko Maki, David Crane, and Aldo Rossi and some others, have provided their viewpoints in this regard. The necessity of addressing the issue of cities' identity is considerable from two points of view. The first is "what consequences does the lack of consideration of cities' identity, especially ancient cities have?", and the other one is that given the current conditions "which methods can have the maximum efficiency for development of cities?". In order to study the city's identity, its physique and organization are more tangible and more stable, and provide a strong point to start, that other intangible and unstable aspects can be associated to. This study is aimed to compare the identity structure of the society to the physical structure of the city and its establishment through the correspondence of component, hierarchies, constituents and aspects of identity structure with physical structure. In this study, descriptive and comparative methods were used: first, key concepts have been illustrated in theoretical basis and then the "identity structure" and "physical structure" models have been constructed and provided using the "structure theory" as the basic theory of this study. Then, components, hierarchies, constituents, and aspects of identity structure were compared to components, hierarchies, constituents, and aspects of physical structure.

\section{Article layout}

\section{Theoretical model of identity structure of the society}

The manner of the style, order and arrangement of the component's shape of different phenomena, leads to the phenomenon called structure. These components are consisted of division units, connectors, joints, and boundaries. For example, the method of arrangement, deployment, and form of urban elements such as houses, shops, mosques, schools, clinics, parks, and so on, which have relation and interaction with each other and provide a product, is called structure (Noormohamadzad, Behzadfar 2011)

According to the "structure theory", components of a phenomenon are related to each other by transformators, around regulators and in adherence to principles, and create the structure of that phenomenon.

Therefore, in order to model the structure of a phenomenon, four points have been considered:

- Components, which have the entity-constructing role.

- Transformators, which are actions and behaviors that create the structure.

- Regulators, which are rules that the structure components are arranged around them. Regulators have the regulation role.

- Principles, which are the unchangeable issues that have the forming role (Ibid).

Due to the extent of identity concept, and diversity of various points of view to model the "identity structure", first, the identity components have been recognized and "general model of identity" has been provided, and then, "general model of identity structure" has been created based on it. 


\section{Components of identity structure}

Identity components from the viewpoint of Dariush Shaygan are thought, language, and art (Ghezelsofla, Maashsani 2010).

- Thought

Thought is a current in which our knowledge is gathered to reach a new result. In other words, thought is the organization and reorganization in our past learning to use in our current position (Solso 2002). Therefore, thought is a cognitive process that sometimes tends toward the behavior and leads to it, and sometimes seeks a way to solve a problem (Ibid).

The bases of thought are two things: Remark and Ethnic memory (Fig. 1).

Ethnic memory actually provides most of patterns, knowledge and behaviors for people and there is no need to personal innovation. In traditional society that ethnic memory is still influential, thought is actually remark. In other words, ethnic memory is like a graceful fountain which benefits everyone regarding their effort and talent (Shayegan 1993).

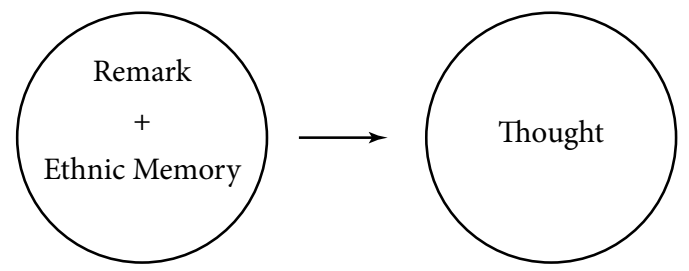

Fig. 1. Components of Thought (authors based on Shayegan 1993)

\section{- Language}

Language is an ability allocated to the species that due to the natural selection has been evolved in human (Parsa 1997). Language, is not only an interface of external relationship between people, but also an internal interface which we use to think, represent and organize our external world (Ibid).

In fact, language is a mental system that appears as a phonetic instrument and its main role is to establish communication and transfer data between people (Fig. 2). People communicate with each other by applying the language rules and production of various strings of words. Hence, it is clear that the language is greatly combined with human life, both his mental and dynamic activities. In addition, language is associated with him from almost the beginning to the end of life. On the other hand, language undoubtedly has a lot of impact on regulation and development of thought which is also another distinguishing feature of human mind (Meshkatodini 1994). In other words, differences in thought are determined through the language (Parsa 1997).
In most discussions about identity (either today or in the past), language has been emphasized more than anything. Specifically, after the reign of Reza Shah, such an approach can be seen in most works of our visionaries. For example "Fakhrodin Shadman" believed that "Iranian identity" is identified through language, and language is the link which have brought us together. Undoubtedly, language is the major and important foundation of each society's identity (Saniejlal 2005).

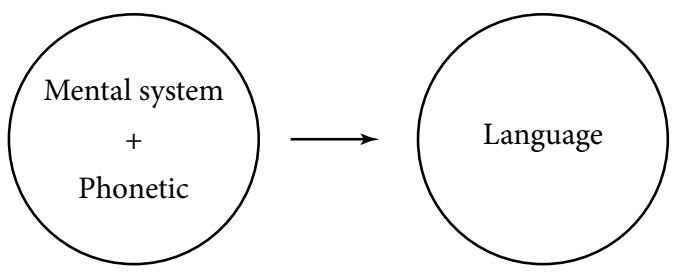

Fig. 2. Components of Language (authors based on Meshkatodini 1994)

- Art

Art is the expression of any ideal into a visual form by the artist (Fig. 3). The spontaneous motivations that get the artist to express his/her mind into visualization, is not clear; although, undoubtedly it can be illustrated in terms of physiology. Visualization by itself cannot create an artwork. So far, it can be said that although the artwork always involves visualization, every visualization is not necessarily an artwork. In other words, the art is every visualization which is affected by sensitivity (Read 2007).

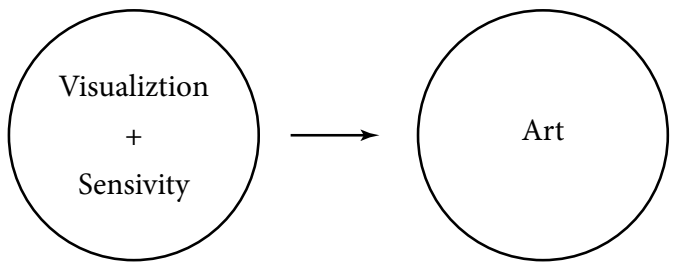

Fig. 3. Components of art (authors based on Read 2007)

\section{- Environment}

In geography and environmental psychology, the question that "Who are we?" often and thoroughly is related to the question "Where are we?" (Dixon, Durrheim 2000 as cited in Sharifi et al. 2013). Totality and the major backbone of character of each human, which determines his/her identity, is a place that he/ she recognizes himself/herself by it and introduces to others. When he/she thinks about himself/herself, and is attached to that place, and considers the place as a part of him/her, parity with the place is created (Pakzad 1996). Guy Rocher believes that a person develops his/her identity through the different environments to where he belongs or refers (Rocher 1991). In fact, people refer themselves to physical environments as a place, than the social environments. Places 
of residence, somewhat determine the human identity and vice versa; places are affected by human identity (Nasar, Kang 1999 as cited in Sharifi et al. 2013).

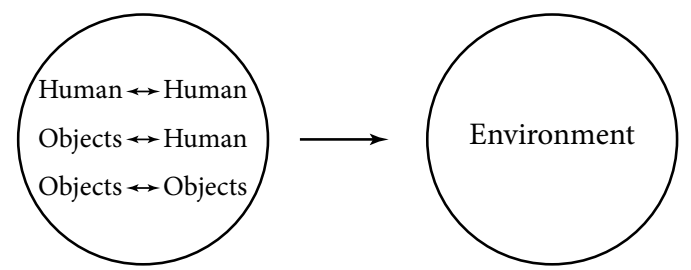

Fig. 4. Environment Model (authors based on Rapoport 2005)

In this study, the concept of the place is not the model that Kanter has introduced for place, but an environment that involves human. The environment includes a set of behavioral stations which are located in each other and have common points with each other. The main elements of these behavioral stations are pattern of behavior index and physical environment (Pourjafar et al. 2011). Alexander after referring to a "Nameless quality" which leads to survival of buildings and cities, states that: "In order to define the quality of buildings and cities, we must begin with the understanding that identity of each space is obtained by continuous repletion of certain patterns of events in that place" (Alexander 2006). Rapoport introduces the environment as the result of meaningful communication. In his view, the environment can be seen as a series of relations between objects and objects, objects and human, human and human (Fig. 4). These relations are arranged. They have structure and pattern (Rapoport 2005).

Based on the above-mentioned the general model of identity is presented in Figure 5.

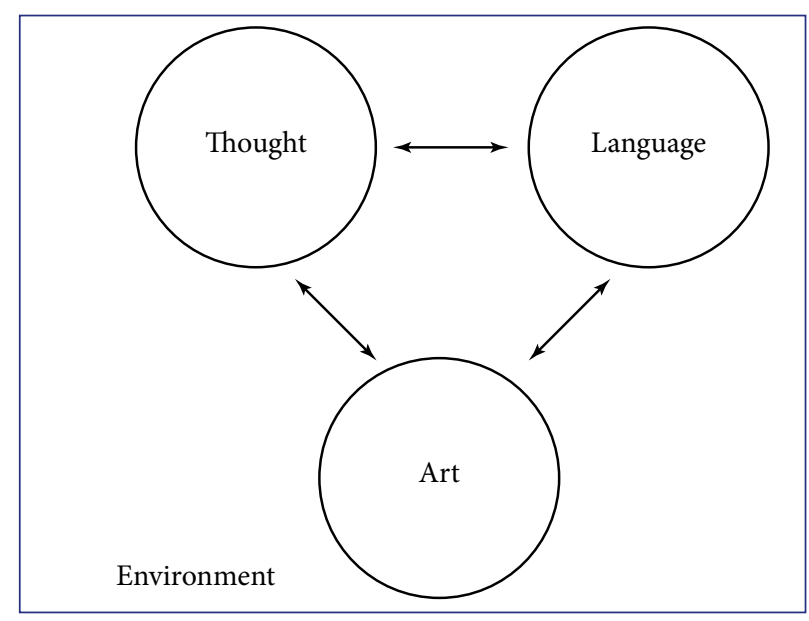

Fig. 5. The general model of identity (authors based on Shayegan 1993; Rapoport 2005)

- Similarity-Dissimilarity

Furthermore, identity has two original meanings. The first meaning represents the concept of absolute similarity (Something is similar to another). The second meaning is dissimilarity that over the passage of time, assumes the consistency and continuity (Fig. 6). Thus, the concept of similarity can be achieved from two aspects, and the identity simultaneously establishes two possible relations between people or objects, similarity from one side and dissimilarity from the other side (Moharrami 2004).

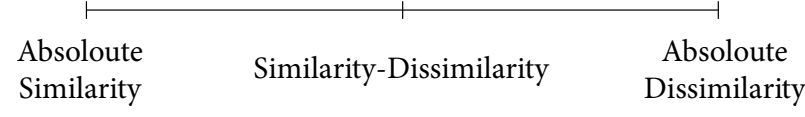

Fig. 6. Identity as a spectrum from similarity to dissimilarity (authors based on Woodward 2000)

Accordingly, in the general model of identity, the stronger the relations between components are, the more similarities and less dissimilarities will be found; and vice versa, the weaker the relations between components are, less similarities and more dissimilarities will be found.

\section{Transformators of identity structure}

Grammatical transformators are functions which are applied on division units to produce the structure. The first division unit, in each hierarchy, acts as a generator that with application of the specified transformators, the second division unit is formed. Then, the second division unit, as the generator, forms the third level structure, with application of transformators. This process will be continued to build the desired structure. In any language, specific transformation rules are formed based on the functionality of major transformators. There are three major transformators that may be used in formulation of specific transformation rules: increment, replacement, and removal (Meshkatodini 1994). Formation, stabilization, communication, inspiration, production, establishment, and provision are the sub-transformators of identity structure which are formed based on major transformators and create the identity structure of the society.

\section{Regulators of identity structure}

Specific grammatical processes that construct the structure of phenomenon by applying appropriate changes on division units are called transformation rules (or grammatical transformators). To achieve the structure of a phenomenon from a generator, transformators are needed which are applied by some rules. These rules are called regulators. In order to produce an appropriate structure, a specific change is applied on generators through the transformation rules. In some cases, it is necessary to apply some correlated transformators on a chain of generators to create desired structure. (Meshkatodini 1994). 


\section{Principles of identity structure of the society}

The hierarchy principle is one of the principles that is respected in general by all the phenomena, therefore the identity structure also adheres to this principle. Accordingly, the identity structure has levels.

\section{- Levels of identity structure}

Identity has various levels. These levels may include from the lowest level - individual, to the highest level nation and even international community. Each level consists of elements that people's sense of belonging to them are different. Some of these elements form the identity foundation of the individual; hence, the individual is more sensitive toward them and show more obvious reaction; so that rejects any violation to them (Goodarzi 2005). Castells argues that identity means the essence and existence of an individual, society, and a nation (Castells 1997 as cited in Karimi 2007). Motahari argues that the smallest social unit is the family. A unit greater than the family, is the tribe, which includes a set of families having high similarities, and this form of life is more evolved than the family life. There is a larger and more evolved social unit called nation, consisting of people with a unique government and law, that governs them (Motahari 1983).

Common elements among the above categories are individual, family, group, society, nation and the world, which are classified as the levels of identity from the lowest to the highest.

Therefore, the components of identity can be tracked in each of these levels that are presented in Table 1.

The principles which identity specifically adheres to, are "originality principle" and "contemporaneous Principle". The identity is a phenomenon appeared with two profiles. One represents "stability" and its reflection in the society and social behavior that is appeared as the "originality", and the other represents "change" and its reflection in the society and social behavior that is appeared as the "contemporaneous". The reflection of such perception can be expressed in two concepts, "quiddity" and "essence". "Quiddity" refers to the "point of similarity" and essence emphasizes its "continuity line". In this semantic area, it is noteworthy that the human, in addition to the "existence" as the "underlying identity", has an "individual existence" called "main identity". When we asked: "what are you and who are you?" undoubtedly we mean that whether you know your similarities and attachment origin of human and individual existence? Whether you know your main and underlying identity? (Motaharnia 2015).

Another consequence of this perception is that: if we don't know who we were, so we cannot know who we are; in other words, the recognition of our existence depends on our historical knowledge and until we don't know how we reach current position, we cannot plan to reach our goal position without harming our identity. Now, by recognizing and understanding the strategic depth of identity and in the light of identity identification in above-mentioned issues, we can define identity. Identity is the meaningful and defined existence of human or human sets that in their historical life tunnel have been preserved and continued, in the realm of existence and availability, so that distinguishes him from other creatures as a human, and in the position of a person, an individual, and a set of individuals, represents their "qualitative unity" in the "Historical plurality” of human life (Ibid).

\section{Identity structure}

National and global levels of identity structure are beyond the scope of this study; therefore in the model of identity structure, we consider four levels including individual, family, group and society as presented in Table 2.

Table 1. Components of identity in hierarchy (authors)

\begin{tabular}{cccc}
\hline Levels & Components & Art & Environment \\
\cline { 2 - 4 } & Thought & Language & Individual's art \\
\hline Individual & Individual's thought & Individual's language & Family's art \\
\hline Group & Family's thought & Family's language & Group's art \\
\hline Society & Group's thought & Group's language & Society's art \\
\hline Nation & Society's thought & Society's language & Group's environment \\
\hline World & Nation's thought & Nation's language & Sation's art
\end{tabular}


Table 2. Presentation of identity structure of the society (authors)

\begin{tabular}{|c|c|c|c|c|c|}
\hline \multirow[b]{2}{*}{ Levels of Identity } & \multicolumn{5}{|c|}{ Identity Structure } \\
\hline & $\begin{array}{l}\text { Components of } \\
\text { Identity }\end{array}$ & Trans & nators & Regulators & Principles \\
\hline Individual & \multirow{4}{*}{$\begin{array}{l}\text { Thought } \\
\text { Language } \\
\text { Art }\end{array}$} & \multirow{4}{*}{$\begin{array}{l}\text { Increment } \\
\text { Replacement } \\
\text { removal }\end{array}$} & Formation & \multirow{4}{*}{ Rules } & \multirow{4}{*}{$\begin{array}{c}\text { Hierarchy } \\
\text { Originality } \\
\text { Contemporaneous }\end{array}$} \\
\hline Family & & & $\begin{array}{l}\text { Stabilization } \\
\text { Communication }\end{array}$ & & \\
\hline Group & & & $\begin{array}{l}\text { Inspiration } \\
\text { Production }\end{array}$ & & \\
\hline Society & & & $\begin{array}{l}\text { Establishment } \\
\text { Provision }\end{array}$ & & \\
\hline
\end{tabular}

\section{Theoretical model of physical structure of the city}

Physique is the frame of everything (Dehkhoda 1994). The physique means the frame of everything, body of human, and exemplary (Moin 1974). The physical structure of the city is not only consisted of various elements, but also represents the relations of these elements with each other and the attempt to adapting themselves to the general shape of the collection (Bazrgar 2003). In this study, general theoretical model of physical structure of the city has been created and provided given the general model of structure. As previously mentioned, shapes of components of the city physique (including, division units, connectors, joints, and boundaries) are related to each other by transformators, around regulators and in adherence to principles, and create the physical structure of the city (Noormohamadzad, Behzadfar 2011). Later, shapes of the components, transformators, regulators and principles are investigated.

\section{Components of physical structure}

As mentioned, the physique is a frame. Frame is a set of things which create the body. In other words, a set of everything which is placed in the body, creates the frame. Physique is formed through the flexible material, in other words, flexible material reveals a form of nature and truth in each of its appearances. Material is simply a thing that is potentially flexible, in other words, is formable. According to Aristotle, form is considered as the material organizer that shows his emphasize on the role of form (Nowrouzitalab 2010). Form is the intuitive and obvious manifestation of a phenomenon that exposes itself to judgment (Grutter 1996). Form is the appearance, structure and growth pattern of the content and its expression (Cagan as cited in Pakzad 2010). Form is affected by the content (Grutter 1996). No form can be imagined without content, and no content can be imagined without form. Content is an issue, a meaning, and a concept which is lied in a phenomenon (Pakzad 2010). Accordingly, physique is formed in material and also form is affected by the content. Therefore, the intersection of form, material, and content, create the physique of a phenomenon (Fig. 7).

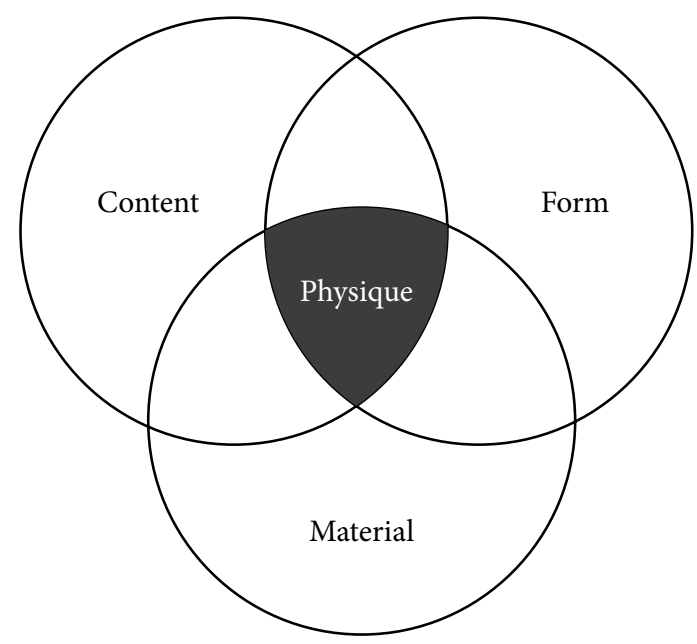

Fig. 7. The general model of physique (authors)

Based on the structure theory on physical structure, division units are defined as the shape of the intersection of form, material and content. The intersection shape of division units (intersection of form, material, and content) creates connectors. The shape of connectors' confluence (intersection of division units) creates joints. The shape of most outer limit of division units (intersection of form, material and content) forms the boundary (Fig. 8).

\section{Transformators of physical structure}

The main transformators of physical structure of the city are generation, arrangement, style, order, and deployment, which are applied on structure components in various levels by sub-transformators including repetition, adjacency, compost, connection, appearing, relation, forming, provision, organizing, and creation. The first component is considered as the generator, that by generation, structure components are produced, and then, structure is formed by applying other transformators on it. 


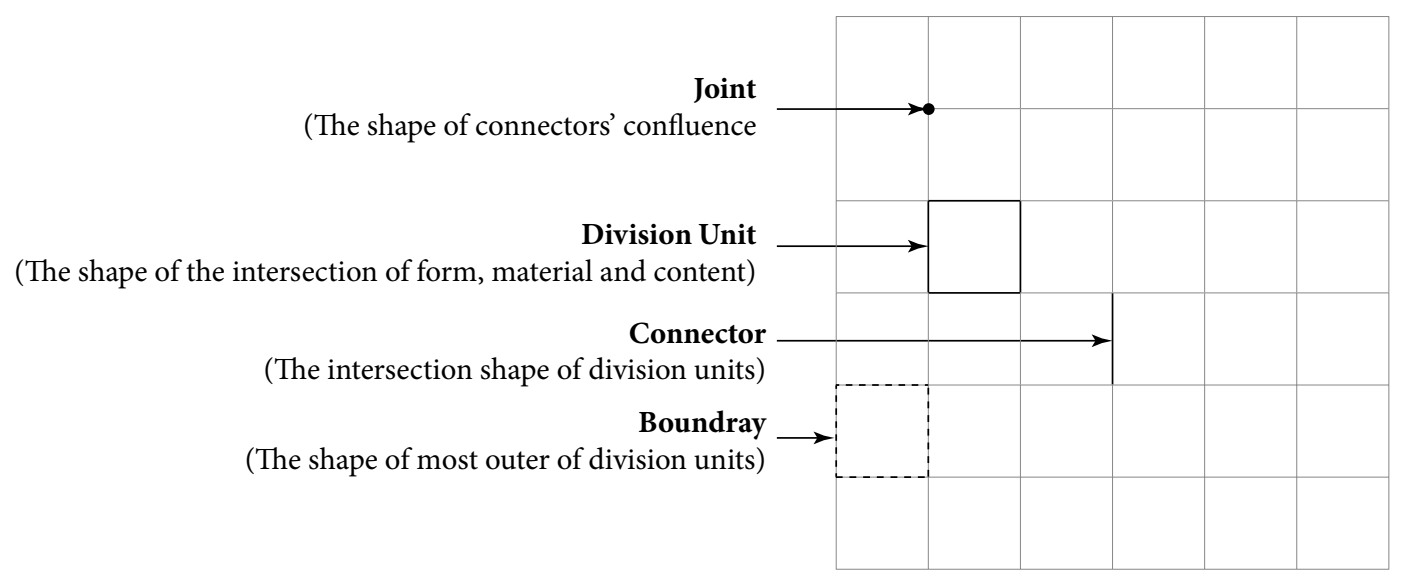

Fig. 8. The general model of components of physical structure (authors based on Noormohamadzad, Behzadfar 2011)

\section{Regulators of physical structure}

Three major organizing types can be considered for systems: central organization, linear organization, and free organization. Pure and main organization is rarely possible; in most cases, either we are facing with similar types or combination of these systems (Grutter 1996). In addition to three above-mentioned types, radial, collective and network systems are also considered (Ching 2006). The order of considered system is the effect of these regulators: center, axe (line) and assumptive factor (line, surface, and volume).

\section{Principles of physical structure}

Physical structure is in adherence to principles, in other words, principles form this structure. Each principle plays a specific role in forming the physical struc- ture. Several principles including hierarchy, proportionality, preferential patterns, continuity, repetition, proximity, arrangement, and limitation are various principles of physical structure (Noormohamadzad, Behzadfar 2011).

\section{- Levels of physical structure}

Physical structure is in adherence to hierarchy. Physique is created of various levels. These levels are consisted of physical structure of particle, blocks, superblocks, sectors, and their inner and outer relations in the environment (Noormohamadzad, Behzadfar 2011). These components in the particle level are physical shape of particles, deadlocks, boundaries, entrances, crossing point of boundaries, physical boundary of particles. In block level, these components are physical shape of blocks, alleys, boundaries,

Table 3. Components of physical structure in hierarchy (authors based on Noormohamadzad, Behzadfar 2011)

\begin{tabular}{|c|c|c|c|c|}
\hline \multirow{2}{*}{ Levels } & \multicolumn{4}{|c|}{ Components of physical structure } \\
\hline & Division unit & Connector & Joint & Boundary \\
\hline Particle & $\begin{array}{l}\text { Physical shape of } \\
\text { particle (intersect of } \\
\text { form, material and } \\
\text { content) }\end{array}$ & $\begin{array}{c}\text { The shapes of } \\
\text { intersection of physical } \\
\text { particles: the shape } \\
\text { of deadlock and } \\
\text { boundaries }\end{array}$ & $\begin{array}{l}\text { The shapes of } \\
\text { intersection of } \\
\text { connectors: the shape } \\
\text { of entrances, crossing } \\
\text { point of boundaries }\end{array}$ & $\begin{array}{c}\text { The shape of most outer } \\
\text { limit of physique of } \\
\text { particles: the shape of } \\
\text { boundary of particle's } \\
\text { physique }\end{array}$ \\
\hline Block & $\begin{array}{l}\text { physical shape of blocks } \\
\text { (intersect of form, } \\
\text { material and content) }\end{array}$ & $\begin{array}{l}\text { The shapes of } \\
\text { intersection of physical } \\
\text { blocks: the shape of } \\
\text { alleys and boundaries }\end{array}$ & $\begin{array}{c}\text { The shapes of } \\
\text { intersection of } \\
\text { connectors: the shape of } \\
\text { intersections, squares, } \\
\text { points }\end{array}$ & $\begin{array}{l}\text { The shape of most } \\
\text { outer limit of physique } \\
\text { of blocks: the shape } \\
\text { of boundary of blocks' } \\
\text { physique }\end{array}$ \\
\hline Superblock & $\begin{array}{c}\text { physical shape of } \\
\text { superblocks (intersect } \\
\text { of form, material and } \\
\text { content) }\end{array}$ & $\begin{array}{c}\text { The shapes of } \\
\text { intersection of physical } \\
\text { superblocks: the shape } \\
\text { of secondary passes and } \\
\text { boundaries }\end{array}$ & $\begin{array}{l}\text { The shapes of } \\
\text { intersection of } \\
\text { connectors: the shape of } \\
\text { intersections and points }\end{array}$ & $\begin{array}{l}\text { The shape of most } \\
\text { outer limit of physique } \\
\text { of superblocks: the } \\
\text { shape of boundary of } \\
\text { superblocks' physique }\end{array}$ \\
\hline Sector & $\begin{array}{l}\text { physical shape of sectors } \\
\text { (intersect of form, } \\
\text { material and content) }\end{array}$ & $\begin{array}{c}\text { The shapes of } \\
\text { intersection of physical } \\
\text { sectors: the shape } \\
\text { of main passes and } \\
\text { boundaries }\end{array}$ & $\begin{array}{c}\text { The shapes of } \\
\text { intersection of } \\
\text { connectors: the shape of } \\
\text { intersections, squares, } \\
\text { crossroads }\end{array}$ & $\begin{array}{c}\text { The shape of most } \\
\text { outer limit of physique } \\
\text { of sectors: the shape } \\
\text { of boundary of sectors' } \\
\text { physique }\end{array}$ \\
\hline
\end{tabular}


intersections, squares, points and boundaries of physique of blocks. In the superblock level, components of physical structure are physical shape of superblocks, secondary passes, boundaries, intersections, points and boundary of physique of superblocks. In the sector level, components of physical structure are physical shapes of sectors, main passes, boundaries, intersections, squares, crossroads, and boundary of physique of sectors.

Hence, components of physique can be tracked in each of these levels that are presented in Table 3.

\section{Physical structure}

In the physical structure of particle level, the shapes of particles' physique are division units; the shape of deadlocks and boundaries are connectors. The shape of entrances and crossing points of boundaries are considered as joints. They have created various structural links. In the physical structure of block level, the shape of each block's physique is considered as a division unit. The shape of alleys and also boundaries, are the connectors. The shape of intersections, squares and points are considered as the joints of this structure. Blocks are separated from each other by boundaries. In the structure of superblock level, the shape of each superblock's physique is a division unit. The shape of intersection of superblocks, are connectors of this level. Connectors are shapes of secondary passes and boundaries of superblocks. The shape of intersections and points are considered as the joints of this structure. Superblocks are separated from each other by boundaries. In the structure of sector level, the shape of each sector's physique is considered as a division unit. Division units are related to each other through the connectors. The shape of main passes and boundaries, are the connectors of the sector's structure. The shape of intersections, squares, and crossroads are joints of this level. Each sector has its own specific boundary (Noormohamadzad, Behzadfar 2011). The components of physical structure of the city are presented in Figure 9.

Based on the above-mentioned the physical structure of the city is presented in Table 4.

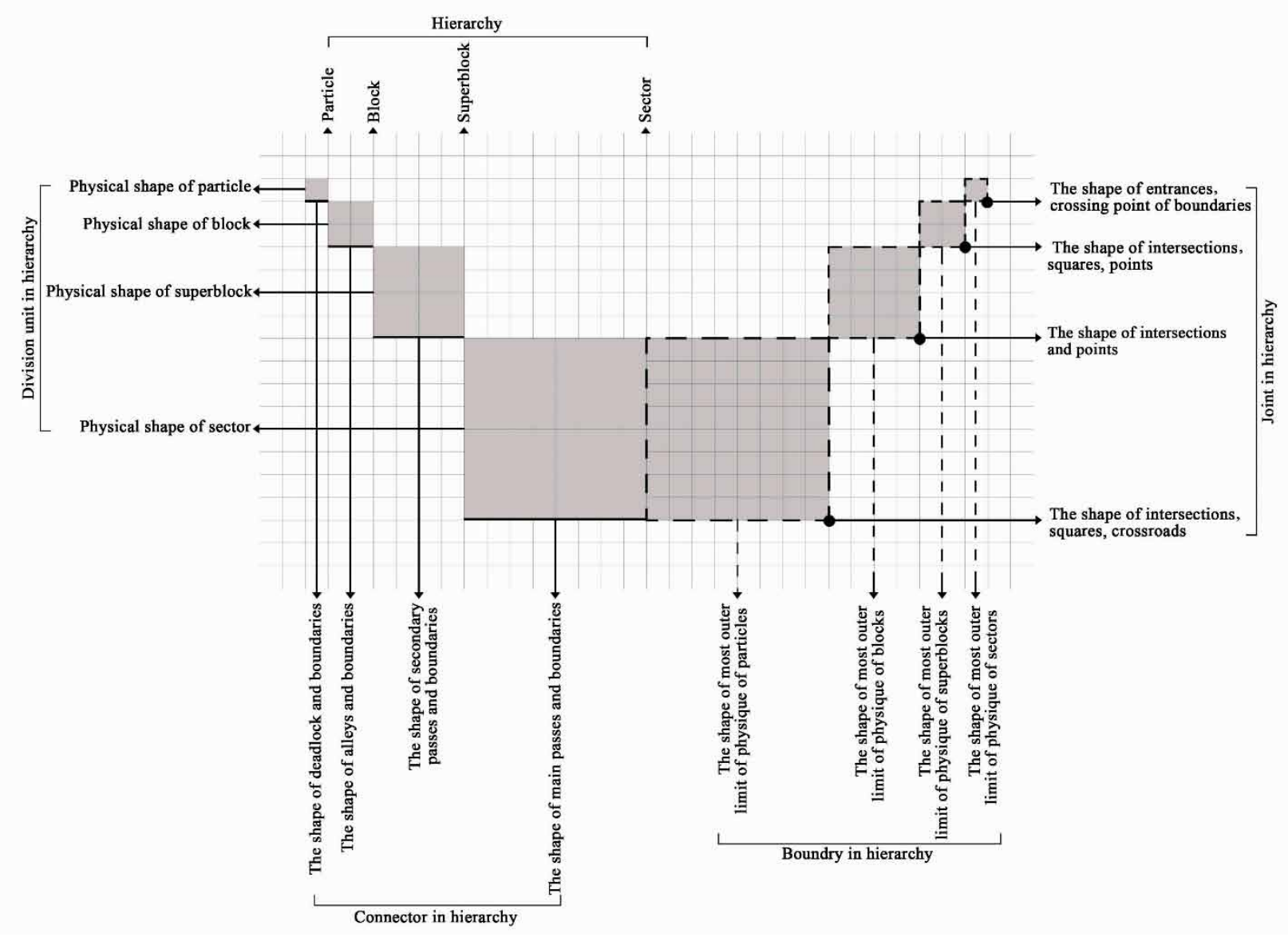

Fig. 9. Components of physical structure model (authors) 
Table 4. presentation of physical structure of the city (authors)

\begin{tabular}{|c|c|c|c|c|c|}
\hline \multirow{2}{*}{$\begin{array}{l}\text { Levels of } \\
\text { Physique }\end{array}$} & \multicolumn{5}{|c|}{ Physical Structure } \\
\hline & Components of Physique & Transfor & ators & Regulators & Principles \\
\hline Particle & $\begin{array}{l}\text { Physical shape of particles, deadlocks } \\
\text { and boundaries, entrances, crossing } \\
\text { point of boundaries and the shape of } \\
\text { boundary of particle's physique }\end{array}$ & \multirow{4}{*}{$\begin{array}{c}\text { Generation } \\
\text { Arrangement } \\
\text { Style } \\
\text { Order } \\
\text { Deployment }\end{array}$} & \multirow{4}{*}{$\begin{array}{l}\text { Repetition } \\
\text { Adjacency } \\
\text { Compost } \\
\text { Connection } \\
\text { Appearing } \\
\text { Relation } \\
\text { Forming } \\
\text { Provision } \\
\text { Organizing } \\
\text { Creation }\end{array}$} & \multirow{4}{*}{$\begin{array}{l}\text { Center } \\
\text { Axe } \\
\text { Assumptive } \\
\text { factor }\end{array}$} & \multirow{4}{*}{$\begin{array}{l}\text { Hierarchy } \\
\text { Proportionality } \\
\text { Preferential } \\
\text { patterns } \\
\text { Continuity } \\
\text { Repetition } \\
\text { Proximity } \\
\text { Arrangement } \\
\text { Limitation }\end{array}$} \\
\hline Block & $\begin{array}{l}\text { physical shape of blocks, alleys and } \\
\text { boundaries, intersections, squares, } \\
\text { points and the shape of boundary of } \\
\text { blocks' physique }\end{array}$ & & & & \\
\hline Superblock & $\begin{array}{l}\text { physical shape of superblocks, } \\
\text { secondary passes and boundaries, } \\
\text { intersections, points and the shape of } \\
\text { boundary of superblocks' physique }\end{array}$ & & & & \\
\hline Sector & $\begin{array}{l}\text { physical shape of sectors, main passes } \\
\text { and boundaries, intersections, squares, } \\
\text { crossroads and the shape of boundary } \\
\text { of sectors' physique }\end{array}$ & & & & \\
\hline
\end{tabular}

\section{Findings}

\section{Comparison between identity structure of the society and physical structure of the city}

Components and constituents of city identity, is similar to the component and constituents of human identity which is considered as the research issue of psychologists and socialists. City is considered as a specific context for identity studies. City provides opportunities that people act more freely both in choosing their desire identity and adoption of its structure method due to choosing "other" and evaluating the similarities and dissimilarities to given another (Behzadfar 2008). What is mentioned below is the comparison between the identity structure of the society and physical structure of the city. Comparison is possible if there are similarities and dissimilarities between phenomena (Arabi 2003). Therefore, in this study, intersections of identity structure and physical structure have been compared through the correspondence.

\section{Correspondence of the hierarchies of the identity structure with the hierarchies of physical structure}

As previously mentioned, the individual is the generator of society; this means that some individuals create the family, some families create the group and hence, a set of groups create the society. On the other hand, particle is the generator of the city; some particles create block, some blocks create superblock, and a set of superblocks create sectors of a city. Corresponding levels of identity structure and physical structure from lowest to highest is presented in Table 5 .
Table 5. Corresponding levels of identity structure and physical structure (authors)

\begin{tabular}{cc}
\hline Levels of Identity Structure & Levels of Physical Structure \\
\hline Individual & Particle \\
\hline Family & Block \\
\hline Group & Superblock \\
\hline Society & Sector \\
\hline
\end{tabular}

Correspondence of the components of the identity structure with the components of physical structure

Based on the structure theory, components of identity structure and physical structure are division units, connectors, joints, and boundaries which are proposed in different levels, and introduced in the identity structure model and physical structure model. In Table 6 these corresponding components are presented in four levels.

\section{Correspondence of the constituents of the identity structure with the constituents of physical structure}

In order to compare the "identity structure" with the "physical structure", it is necessary to establish the intersections of constituents and aspects of identity structure with the physical structure. In order to find these intersections, in Table 7, correspondence of constituents including "continuity", "integrity", "individuation", "equipoise", "homogeneity", and "parity", from the identity structure is established by the constituents including "position", "shape", "size" and "elongation", from the physical structure. These constituents have 
Table 6. Corresponding components of identity structure and physical structure in hierarchy (authors)

\begin{tabular}{|c|c|c|c|}
\hline Level & $\begin{array}{l}\text { Components of Identity } \\
\text { Structure }\end{array}$ & Components of Physical Structure & $\begin{array}{l}\text { Components of } \\
\text { Structure }\end{array}$ \\
\hline \multirow{4}{*}{ Individual-Particle } & Individual's thought & Physical shape of particle & Division Unit \\
\hline & Individual's language & The shape of deadlock and boundaries & Connector \\
\hline & Individual's art & $\begin{array}{l}\text { The shape of entrances, crossing point of } \\
\text { boundaries }\end{array}$ & Joint \\
\hline & Individual's environment & $\begin{array}{l}\text { The shape of most outer limit of physique of } \\
\text { particles }\end{array}$ & Boundary \\
\hline \multirow{4}{*}{ Family-Block } & Family's thought & Physical shape of blocks & Division Unit \\
\hline & Family's language & The shape of alleys and boundaries & Connector \\
\hline & Family's art & The shape of intersections, squares and points & Joint \\
\hline & Home & $\begin{array}{l}\text { The shape of most outer limit of physique of } \\
\text { blocks }\end{array}$ & Boundary \\
\hline \multirow{4}{*}{ Group-Superblock } & Group's thought & Physical shape of superblocks & Division Unit \\
\hline & Group's language & $\begin{array}{c}\text { The shape of secondary passes and } \\
\text { boundaries }\end{array}$ & Connector \\
\hline & Group's art & The shape of intersections and points & Joint \\
\hline & Group's environment & $\begin{array}{l}\text { The shape of most outer limit of physique of } \\
\text { superblocks }\end{array}$ & Boundary \\
\hline \multirow{4}{*}{ Society-Sector } & Society's thought & Physical shape of sectors & Division Unit \\
\hline & Society's language & The shape of main passes and boundaries & Connector \\
\hline & Society's art & $\begin{array}{l}\text { The shape of intersections, squares, } \\
\text { crossroads }\end{array}$ & Joint \\
\hline & Society & $\begin{array}{l}\text { The shape of most outer limit of physique of } \\
\text { sectors }\end{array}$ & Boundary \\
\hline
\end{tabular}

Table 7. Corresponding constituents and aspects of identity structure and physical structure (authors)

\begin{tabular}{cccc}
\hline $\begin{array}{c}\text { Constituents of Identity } \\
\text { Structure }\end{array}$ & Qualitative Aspects & $\begin{array}{c}\text { Constituents of Physical } \\
\text { Structure }\end{array}$ & $\begin{array}{c}\text { Qualitative and Quantitative } \\
\text { Aspects }\end{array}$ \\
\hline Continuity & Continues & Position & Coordinate \\
\hline Integrity & Correlated & Shape & Boundary \\
\hline Individuation & Unique & Size & Length/ width/ height \\
\cline { 2 - 4 } Equipoise & Distinct & Elongation & Direction \\
\hline Bomoth/ width/ height \\
\cline { 2 - 4 }
\end{tabular}

been extracted from several definitions of "identity" in different sources. Then the aspects have been extracted from the definition of each constituent.

To study the physical structure of cities with the emphasis on the identity structure, in hierarchy, some aspects should be measured. Based on Table 7, in each of the four levels of "individual-particle", "family-block", "group-superblock" and "society-sector" the aspects to measure are: continuous coordinate, correlated boundary, unique length, unique width, unique height, distinct direction, balanced length, balanced width, balanced height, similar length, similar width, 

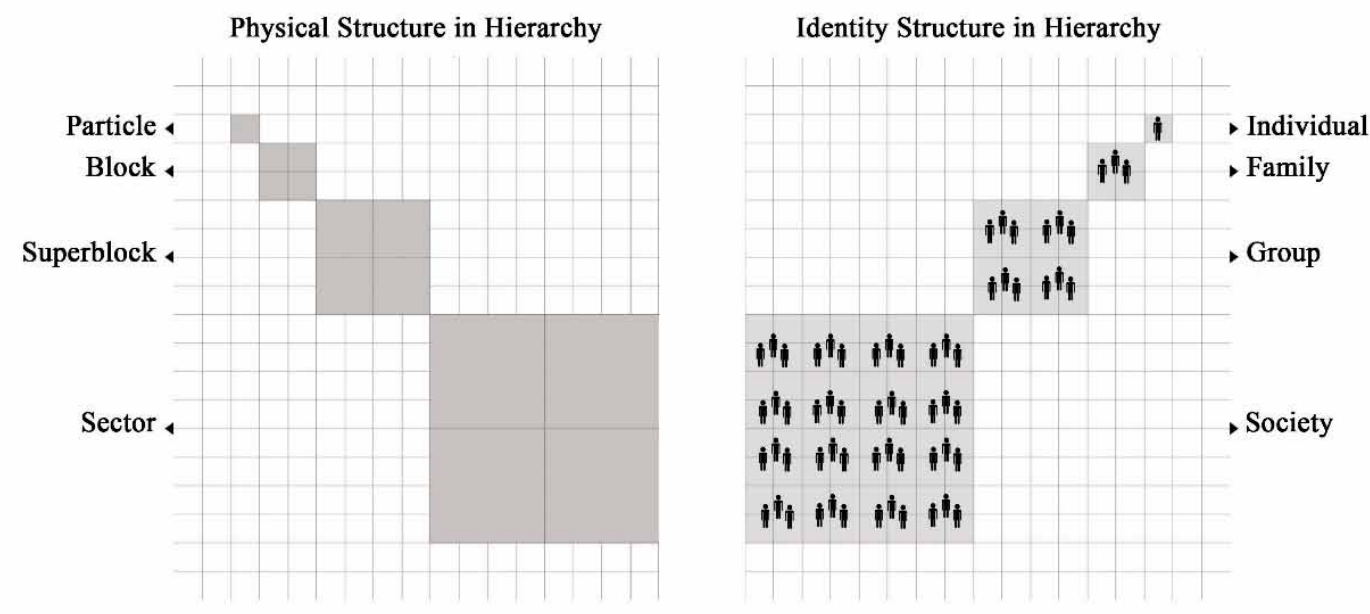

Fig. 10. Correspondence of the identity structure with the physical structure in hierarchy (authors)

similar height, similar direction, similar boundary and memorable boundary. Measuring these aspects will help recognize the problems of the identity structure in the physical structure of the cities. Then appropriate strategies and solutions will be found for the problems based on the specified goals and objectives.

\section{Conclusions}

Structure is a total, consisting of division units, connectors, joints and boundaries which are connected by transformators, around regulators and in adherence to principles. Structure is one of the concepts that can be tracked in different phenomena including identity. By surveying the identity in lower levels and avoiding to roam around this word in surface, identity can be transformed from its theoretical cliché and unreachable concept to an efficient and tangible concept. To reach this, a deductive approach toward identity is needed. Identity is a Total, consisting of language, art and thought, which are connected by transformators, around regulators and in adherence to principles that make identity structure. In the city, studying the physique is the most suitable foundation, on which the outline of identity can be established; for the physique and its organization are the most tangible and stable features of the city. Studying the physique of the city is focused on the form of its components. The physical structure of the city is the resultant of its components' structure, which are connected to each other by transformators, around regulators, and in adherence to the principles. These components are: physical shape of particles, blocks, superblocks and sectors (as division units), the shape of deadlocks, alleys, secondary passes, main passes and boundaries (as connectors), the shape of entrances, crossing point of boundaries, intersections, squares, points, intersections and crossroads (as joints), the shape of most outer limit of physique of particles, blocks, superblocks and sectors (as boundaries).

This survey indicates the correspondence of the identity structure in individual level with the physical structure in particle level. Likewise, the correspondence of the identity structure in family level with the physical structure in block level, the correspondence of the identity structure in group level with the physical structure in superblock level and the correspondence of the identity structure in society level with the physical structure in sector level as represented in Figure 10.

Corresponding levels, components, constituents and aspects of "identity structure of the society" and "physical structure of the city" represent that the identity structure of the society is in accordance with the physical structure of the city. Hence, the similar aspects between these two concepts has been obtained and can be applied in future researches.

\section{References}

Ahmadi, B. 2003. Structure and interpretation of the text. Tehran: Markaz.

Alexander, C. 2006. A pattern language. Tehran: Iranian Urbanism and Architecture Research Center.

Arabi, M. 2003. Comparative study. Tehran: Cultural Research Corporation.

Bazrgar, M. 2003. Urbanism and the main structure of the city. Shiraz: Kooshamehr.

Behzadfar, M. 2008. The identity of the city (looking at the identity of Tehran). Tehran: Shahr Publications.

Ching, F. D. 2006. Architecture, form, space \& order. Tehran: University of Tehran Press.

Dehkhoda, A. 1994. Dehkhoda's encyclopedia. Tehran: University of Tehran Press.

Ghezelsofla, M; Maashsani, S. 2010. Iranian cultural in Dariush Shayegan's viewpoint, Journal of Political Science 5(4): 137171.

Ghotbi, A. 2008. The concept of Iranian identity and modern architecture, Ayene Khial 10: 78-83. 
Goodarzi, H. 2005. The sociology of identity in Iran. Tehran: Institute of National Studies and Iranian Civilization.

Grutter, J. K. 1996. Asthetics in architecture. Tehran: University of Shahid Beheshti Press.

Karimi, A. 2007. Iranian cultural identity reflected in the logbook of the Safavid and Qajar era, National Studies 8(1): 31-62.

Lotfi, S. 2005. Introduction to grammatical structural analysis of city structure, Beautiful Arts 22: 15-24.

Meghdadi, B. 2014. Encyclopedia of literary criticism from Plato to the Present Day. Tehran: Cheshmeh.

Meshkatodini, M. 1994. Farsi grammer based on transformational theory. Mashhad: Ferdowsi University of Mashhad Press.

Moharrami, T. 2004. Iranian-Islamic identity as the basis of Iranian identity, Institute of Humanities and Social Sciences: 65-94.

Moin, M. 1974. A Persian dictionary. Tehran: Amirkabir.

Motahari, M. 1983. Services between Iran and Islam. Qom: Sadra.

Motaharnia, M. 2015. Originality and contemporaneous in identity, Zamaneh 5(43): 65-66.

Motavaf, S. 2007. Identity crisis: challenges of Iranian urbanism in the manifestation of urban regeneration, Baghe Nazar 4(8): 73-80.

Noormohamadzad, H; Behzadfar, M. 2011. Study of physical texture structure of the historical city of Yazd, Architecture and Urbanism Letter 3(6): 71-87.

Nowrouzitalab, A. 2010. An Inquiry into shape and meaning of an artwork, Baghe Nazar 7(14): 69-86.

Pakzad, J. 1996. Identity and parity with space, Soffeh 6: 21-22.

Pakzad, J. 2010. Theoritical and urban design process. Tehran: Ministry of Housing and Urban Development.

Parsa, M. 1997. Introduction to psychology. Tehran: Besat.

Partovi, P. 1999. Structuralism in architecture and urbanism, Honarname 2(5): 104-121.

Piaget, J. 2005. Structuralism. Tehran: Library, Museum and Documentation Center of Islamic Parliament.

Poorafkari, N; Kianpour, M. 2006. Expounds the ideas of Noam Chomsky, Social Sciences 1: 13-30.
Pourjafar, M; Pourmand, H; Zabihi, H; Demne, L. H; Taban, M. 2011. The phenomenology of identity and place in historical context, Journal of Studies On Iranian - Islamic City 1(3): 11-20.

Rapoport, A. 2005. The meaning of the built environment. Tehran: Urban Planning and Process.

Read, H. 2007. The meaning of art. Tehran: Scientific and cultural publications.

Rocher, G. 1991. A general introduction to sociology: a theoretical perspective. Mashhad: Ferdowsi University of Mashhad Press.

Saniejlal, M. 2005. Introduction to Iranian culture and identity. Tehran: Institute of National Studies and Iranian Civilization.

Sharifi, M; Ramesht, M; Rafian, M; Ghavidel, Y. 2013. The space identity ana its perception with geosystematic approach, Geography and Environmental Planning 24(2): 1-22.

Shayegan, D. 1993. Asia agains the West. Tehran: Amirkabir.

Skidmore, W. 1993. Theoretical thinking in sociology. Tehran: Safir.

Solso, R. 2002. Cognitive psychology. Tehran: Roshd.

Woodward, K. 2000. Identity and Difference. United Kingdom: SAGE Publications Ltd.

\section{FARNAZ JAVADI}

holds a Masters in Urban Design from Yazd University, School of Art and Architecture, Iran. Her research interests include: urban structure and urban identity.

\section{HOSSEIN NOORMOHAMADZAD}

is Associate Professor at Yazd University, School of Art and Architecture, Iran. He holds a PHD in Architecture from Iran University of Science and Technology. He is the reviewer of some national journals and his research interests include: urban design, urban planning, and problem diagnose of urban structure and urban texture. He has authored and co-authored peer-reviewed papers and some of his works have been presented and published nationally. 